\title{
Drawing patients closer: five ladies
}

Cite as: CMAJ 2018 June 11;190:E722-3. doi: 10.1503/cmaj.180180

\begin{abstract}
s an intern at the Royal Victoria Hospital in Montréal, I began sketching patients and noting snippets of our conversations. I did this as a way to spend a few extra moments with patients and to focus more closely on their expressions. These drawings bring back the essence of an encounter, a detail of personality and the fragmentary clues that patients are giving to the doctor about their experience with illness. I have continued to sketch, and I awaken each day with the wonderful faces of patients in my mind and their poignant or humorous stories.
\end{abstract}

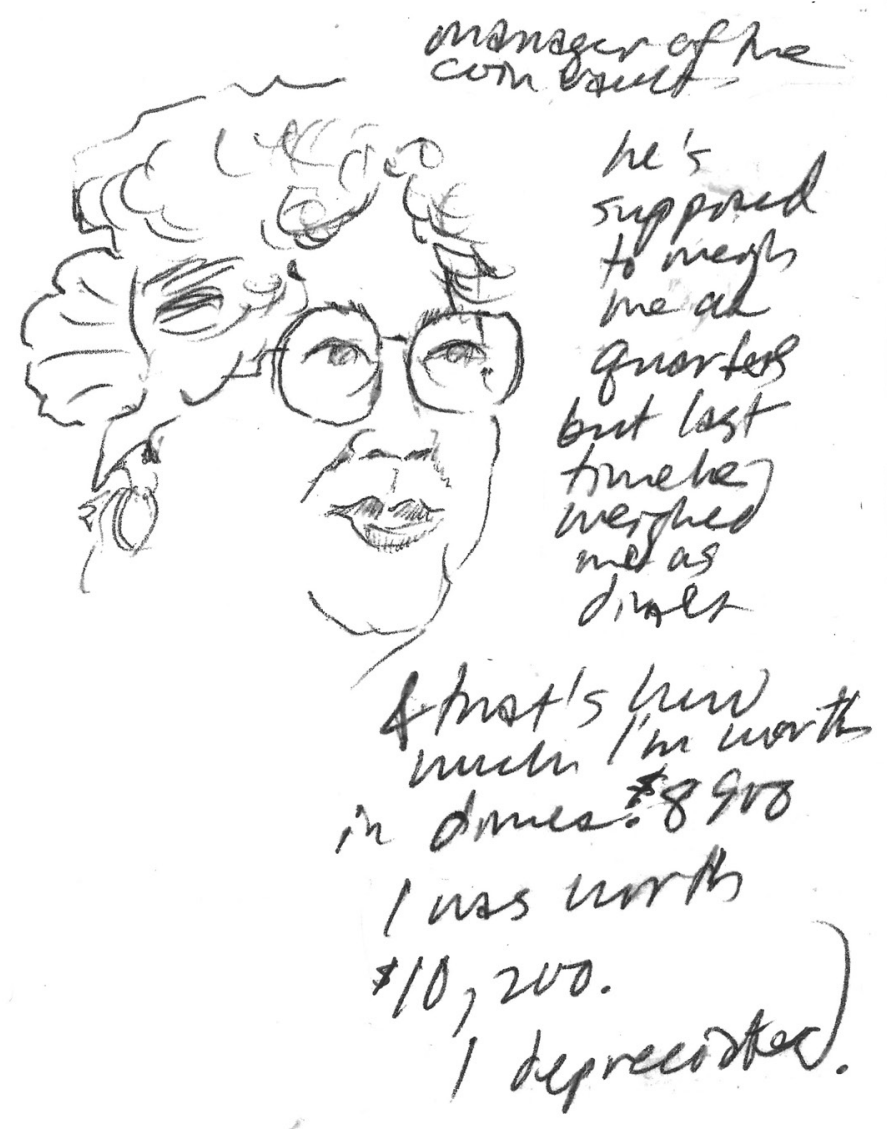

Manager of the coin vault, he's supposed to weigh me as quarters, but last time he weighed me as dimes. And that's how much I'm worth in dimes: $\$ 8900$. I was worth $\$ 10200$. I depreciated.

\section{Alan Blum MD}

University of Alabama School of Medicine, Tuscaloosa, Ala.

This article has been peer reviewed.

These sketches and notes were made more than three decades ago.

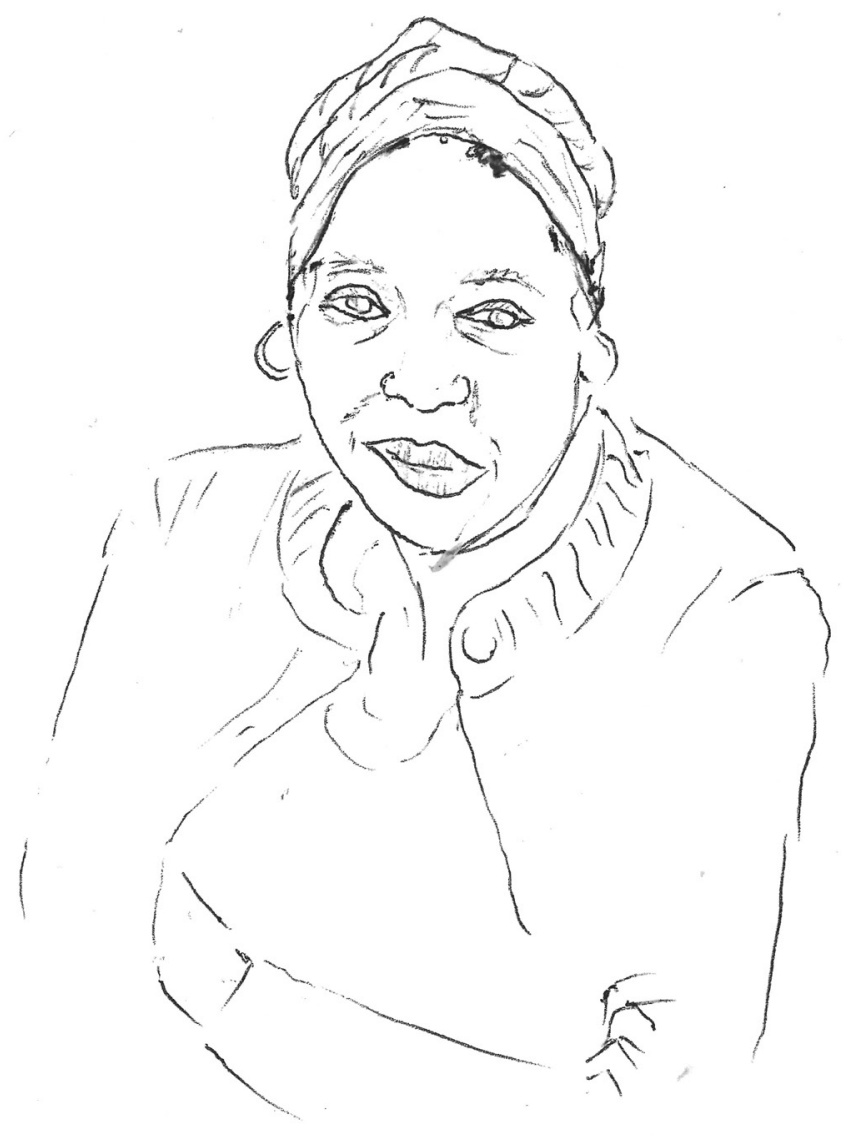

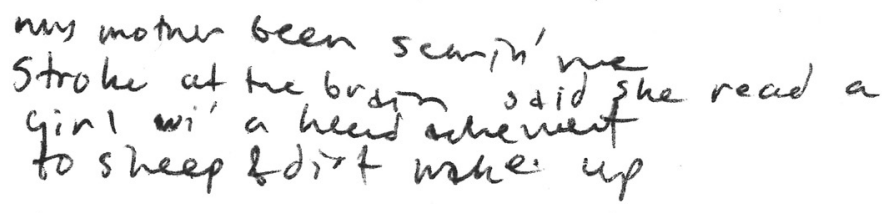

My mother been scarin' me. Stroke at the brain. Said she read a girl wi' a headache went to sleep and din't wake up. 
why do (son you

miant yguthinh ym

mell, to plecuse

him for one thin

of course,

16 (ane my

most of

the thriys

anst go

urang...

TTHINK YOO'RE
An Jotil?

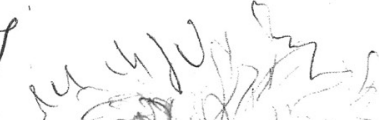

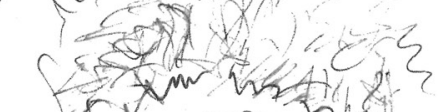

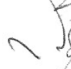

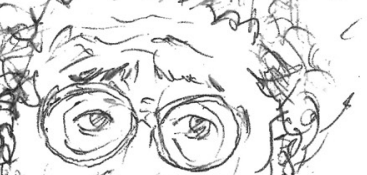

well it's ahro to itsol

strming at he ceiling

\& out the nuivow.

currots,

corn, busgel spronts -

rot brussel

Sprouts -

sprouts
that ing
broccolit

alithe

santeed

mian rulps pasta

louk at me, 1 ase

'men con ( eeet that much?!)
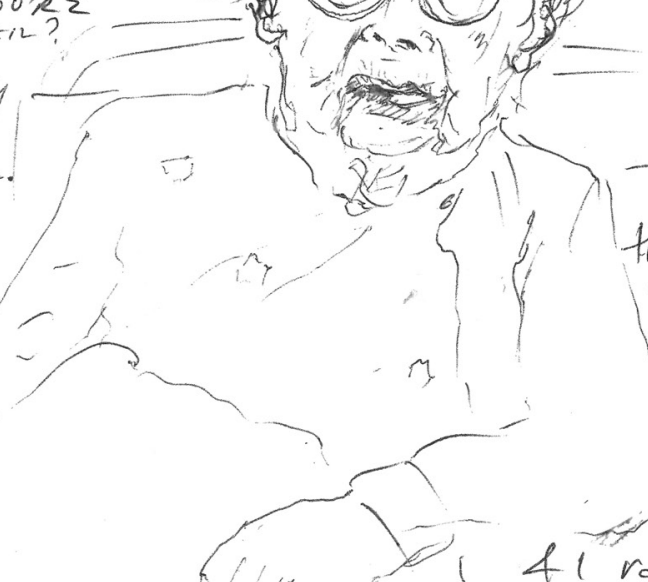

r)

$-$

heus.
Why do you say you think you might die soon? Well, to please him for one thing. Of course, I blame my son for most of the things that go wrong ... Think you're in jail? Well, it's akin to it ... Staring at the ceiling and out the window ... Then I went into the hospital and had a radium transplant in my bowels. I rather like it, because when you're constipated it's hell. So you're losing urine 'cause your sphincter isn't functioning? Not too bad. I can pucker.

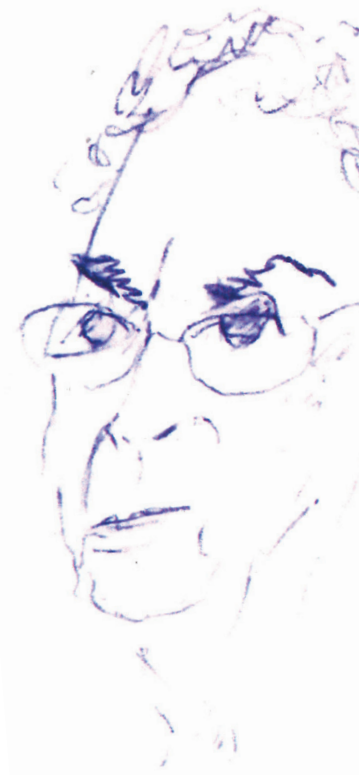

i)

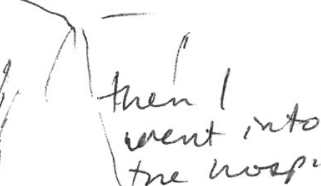

a wad a

rodiom
trangplant
th ung beneds

\&1 ratuer the it

bea. chen you'ne

conctrated it's

sou yin've losing urine 'couse

hot tow bid 